\title{
Rural water service provision by municipalities and CBOs: Performance milestones and KPIs
}

\author{
C Illing ${ }^{1 /}$ and J Gibson ${ }^{2 *}$ \\ ${ }^{1} \mathrm{PO}$ Box 44335, Claremont, 7735, South Africa \\ ${ }^{2}$ Maluti Water, PO Box 1469, Matatiele 4730, South Africa
}

\begin{abstract}
The advantages of using Community Based Organisations for the provision of water services in rural areas have been advocated for some time. These benefits have always been intuitively known, however there is little documentation assessing the real experiences of applying this model of service provision on a large scale within the South African context. This paper describes a process of identifying appropriate targets and monitoring standards that have been implemented in a number of areas in the Eastern Cape where a co-operative approach between Municipalities, CBOs and the private sector has been adopted.

In the absence of readily available performance and costing benchmarks it has proved difficult to compare the tender proposals and indeed the delivery of services from all role-players. A series of cost estimating tools and responsibility milestones have been developed through an empirical process of critically analysing our experiences and developing an operational model from first principles. These milestones are defined in terms of developing the CBO to take on more and more responsibility, as far as is possible, while ensuring an appropriate and cost effective level of service.

The paper will present a number of options that take into account the relative capacity of municipalities and any development process that they may be planning for their own organisation. Critical to the model is that effective delivery of service must be ensured from the start and that any transition as milestones are reached, should be as seamless as possible. Furthermore a series of operational performance indicators and benchmarks are proposed.
\end{abstract}

\section{Introduction}

The widespread use of Community Based Organisations (CBOs) in the operation and maintenance phase of water supply services in rural areas of the Eastern Cape has been hampered by a number of issues:

- Legislative requirements and procedures for the appointment of Water Service Providers (WSP's) (see section 78 of the Municipal Systems Act)

- A lack of readily available information pertaining to key performance indicators and costing benchmarks to implement this model.

- Some suspicion as to the effectiveness of the model.

The Alfred Nzo District Municipality (ANDM) adopted a CBO approach on a pilot basis in 2000 and implemented universal coverage of all water schemes in their area of jurisdiction in July 2002. This approach has enabled them to apply a policy of "free basic water" to a total population of 390000 people at 130 schemes consisting of small stand standalones with populations of less than 500 people through to regional schemes with populations in excess of 20000 people.

\begin{tabular}{|l|c|c|c|}
\hline Area & Schemes & Pop. est. & Cost per capita \\
\hline Umzimvubu South & 36 & 90400 & R2.71 \\
Umzimvubu North & 40 & 190000 & R1.58 \\
Umzimkulu & 56 & 112000 & R3.16 \\
\hline \multicolumn{2}{|l}{ Note: Figures for Jan 04 } \\
\hline
\end{tabular}

This paper was originally presented at the 2004 Water Institute of South Africa (WISA) Biennial Conference, Cape Town, South Africa, 2-6 May 2004.

\# 용 \& Fax: +2721 683-7345; e-mail: Mattcomm@futurenet.co.za

* 푱+2739 737-3563; fax:+2739 737-4267; e-mail: jim@malutiwater.co.za
The ANDM approach consists primarily of utilising CBOs to fulfil as many of the O\&M tasks as possible, particularly day-to-day operation and maintenance (O\&M) and reporting, Support Services Agents (SSAs) are in place to provide technical and training input as required.

Maluti Water and Mattcomm, as a result of their experiences as one of the SSAs on this programme, identified a need for clear goals and targets to be set in terms of the roles and responsibilities of all service providers. As a result of this a series of Key Performance Areas (KPAs), milestones and benchmarks have been developed for the ANDM in the provision of water services to rural communities.

Once such targets, milestones and benchmarks have been defined and adopted it is a simple process to develop a Quality Management System (QMS) that can then be used to ensure continuous improvement of the service delivered and indeed the institutional development of the organisations involved, including CBOs.

A number of generic publications are available that offer guidelines on the use of CBOs in the provision of water services (WRC, 2003). The purpose of this paper is to share our experience from involvement in the ANDM O\&M programme over a period of two years. It is hoped that this will assist other Water Service Authorities (WSAs) and other role players in identifying the most appropriate and cost effective service option to fulfil the water services provider responsibilities. The paper further notes some of the key benchmarks that have been identified and developed through the programme. It is anticipated that these benchmarks will be updated from time to time as service provision improves.

\section{The use of CBOs in water service provision}

The ANDM was the first WSA in the Eastern Cape to implement the large-scale use of CBOs in the provision of water services for their rural schemes. An operational plan was developed, known as the Village Level Action Plan (VLAP)(Alfred Nzo District Mu- 
nicipality, 2000), for all rural schemes in which CBOs and SSAs perform all service provision tasks. The VLAP defines the requirements for setting up of CBOs as well as the relationship between CBOs, SSA and the WSA.

The advantages of using CBOs for rural water service provision include the following:

- Local work done best by local people

- Immediate source of information for operational reports

- Customer relations

- Reduction in vandalism

- Efficiency of operations

- Increased job opportunities at a local level

- Relatively easy and quick to mobilise.

Water Services Authorities do need to recognise that there are certain limitations in the use of CBOs to fulfil all the WSP functions. These limitations can mainly be attributed to the difficult logistics and lack of resources at remote rural schemes.

These limitations include the following:

- Lack of specialist technical services (e.g. engine repairs);

- Administrative requirements of an Employer, (eg. registering with SARS, paying UIF, workmen's compensation, etc);

- Compliance with the necessary financial controls and procedures for the procurement of goods and materials so that they are in accordance with the Councils financial requirements. For example, should need arise to purchase an item or secure services that amount to more than a R1 000.00, the WSA has to authorise payment based on 3 quotations. It would thus be virtually impossible for a CBO based in a rural community without direct access to a fax machine to restore the supply of water within 48 hour turn around period specified by the WSA.

Water services Authorities need to acknowledge these limitations, as well as the fact that CBOs will require varying levels of training in order to fulfil their WSP functions. With this in mind Maluti Water and Mattcomm have identified a CBO-model that accommodates a phased approach, whereby the CBO takes on more responsibilities and functions that were originally fulfilled by the SSA. In addition, this phased approach also allows the WSA sufficient time to gear up its own internal resources without compromising on the level of service being provided at project level.

\section{Methodology}

When developing an O\&M plan it is imperative that WSAs first consider and clearly define the level of service that they wish to be provided. They can then define the specific tasks that must be undertaken, the resources required, and finally, the cost implications. Such a procedure allows for consistency and uniformity in the level of service and the allocation of resources to all schemes within their jurisdiction. Such a systematic approach also allows for more cost effective delivery of services.

The implications and considerations in developing such a vision of the "preferred future" are indicated in figure 1 below. As can be seen, it is necessary for a number of issues to be integrated in developing such a vision. It is suggested that an optimal solution be considered that balances all of the issues. The best solution will be one that attempts to balance all the issues as far as possible, rather than maximising any one issue at he expense of another and thus risking conflict and a reduction in the level of service.

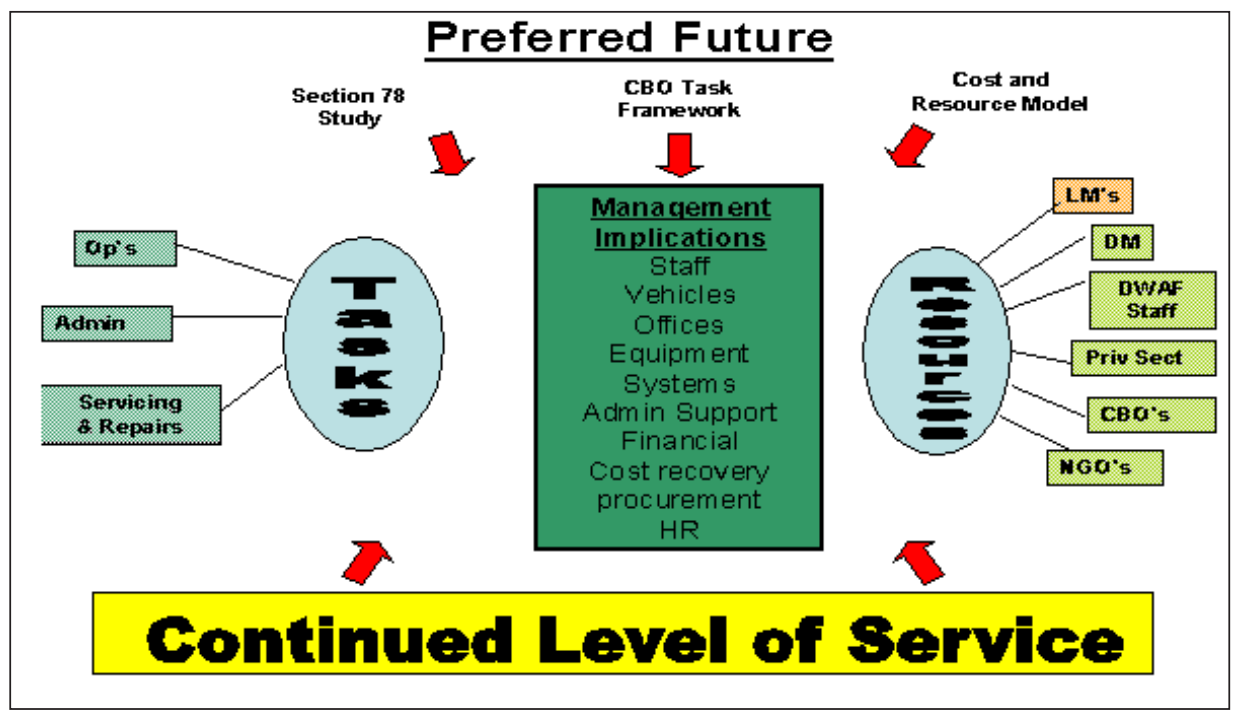

Figure 1

Considerations in formulating an O\&M plan
Through our experiences working on the ANDM O\&M programme, a number of critical steps have been identified:

- Identify the Key Performance Areas (KPAs) of the water service providers

- Identify key milestones (developmental and technical)

- Develop a scheme classification (compare like with like)

- Identify the most appropriate organisations to fulfil the various responsibilities

- Determine financial requirements

- Develop a reporting system

- Establish benchmarks.
In some cases it may be the wish of the WSA to provide the service through a local government organisation even though the capacity does not currently exist within that organisation. In such cases it will be necessary to define a current scenario that can be transformed into the long-term preferences.

\section{Identification of KPAs}

The Key Performance Areas of the Water Service Provider function include the following: 
- Daily operations

- Maintenance

- Administration

- Customer relations and communication

- Reporting
It is suggested that, within each KPA, the WSA needs to identify appropriate management areas and specific output targets or tasks an example of this follows:

\begin{tabular}{|c|c|c|}
\hline \multicolumn{3}{|c|}{$\begin{array}{c}\text { TABLE } 1 \\
\text { Sample of tasks: (Customer Relations and Communication KPA) }\end{array}$} \\
\hline $\begin{array}{l}\text { Key } \\
\text { Performance } \\
\text { Area }\end{array}$ & Management focus & Specific tasks / outputs \\
\hline \multirow{4}{*}{$\begin{array}{l}\text { Customer } \\
\text { relations and } \\
\text { communication }\end{array}$} & Customer care & $\begin{array}{l}\text { - Set up a procedure for dealing with complaints and to respond to } \\
\text { community problems; } \\
\text { - Submit monthly customer care reports to WSA, etc }\end{array}$ \\
\hline & Community report backs & $\begin{array}{l}\text { - Frequency of community report back meetings defined; } \\
\text { - Involvement of ward committees specified, etc. }\end{array}$ \\
\hline & Unauthorised use of water & $\begin{array}{l}\text { - Total number of existing unauthorised connections; } \\
\text { - Total number of new unauthorised connections in the last month, } \\
\text { - Total number of unauthorised connections disconnected, etc }\end{array}$ \\
\hline & Vandalism & $\begin{array}{l}\text { - Total number of incidents of vandalism in the last month; } \\
\text {. Total number of incidents of vandalism in the last } 6 \text { months, etc }\end{array}$ \\
\hline
\end{tabular}

The outcomes of the specific tasks can then be captured in the monthly CBO report that is submitted to the WSA.

\section{Identification of key development milestones}

The provision of water services cannot be delayed while the development of organisational capacity is implemented since such capacity building will be a time-consuming exercise. It is therefore necessary to implement a system that addresses the immediate needs and allows for a transfer of responsibilities as time goes on. A model of such transfer of responsibility is presented in Fig. 2.

Critical milestones that indicate development from one level of tasks to another include the following:

- Contractual agreements between role-players.

- Key policies and by-laws implemented.

- Performance monitoring with measurable achievements.

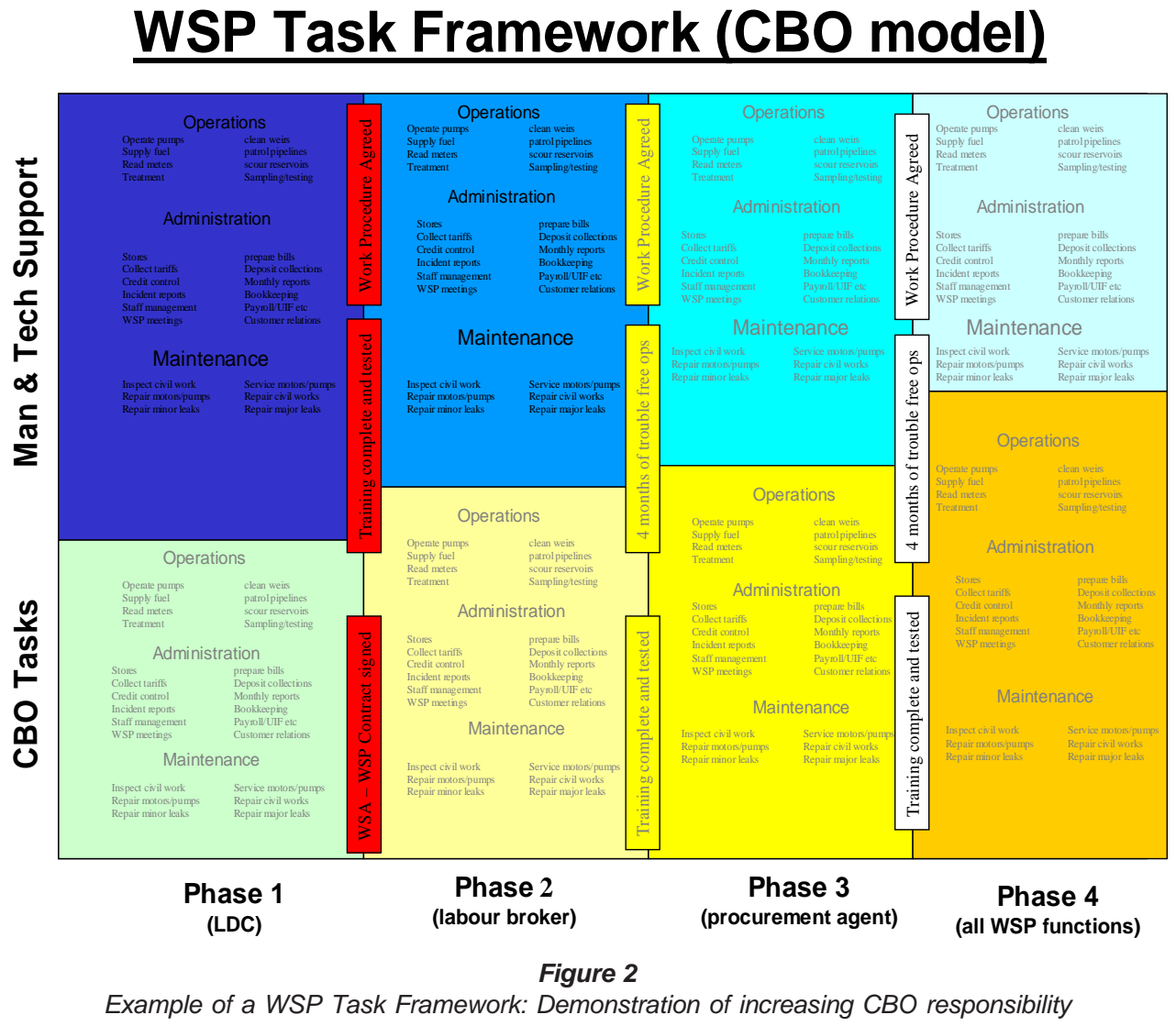

It should be noted that key milestones must apply to both the WSA and the organisations fulfilling the WSP functions, and that progres- sion to the next stage cannot take place until all the role-players have attained their required milestone. 
This model demonstrates how a CBO can progress from their members being employees on limited duration contracts (LDC) through being "labour brokers" (i.e. employing their own staff), to becoming "procurement agents", and finally, status as fully-fledged Water Service Providers. The specific responsibilities in terms of operational, maintenance and administrative should be detailed in contracts or service provision agreements.

It has been our observation that a compromise between delegating responsibility and the resultant monitoring costs may be necessary, particularly when the area is served by many small schemes.

\section{Scheme classification}

It is useful if the WSA classifies schemes in terms of their complexity of O\&M requirements so that the most appropriate and effective resources can be allocated to each scheme and that comparisons between areas of operation can be made.

Factors that need to be considered are the following:

- O\&M costs increase with increased complexity;

- Complexity is a function of both the extent of the scheme (size) and the technological options used.

- Clustering of projects is possible to achieve economies of scale.

The scheme classification system of ANDM works on two parameters:

- Scheme size

- Technology (Table 2).

Each scheme is classed in accordance with its size and technology i.e. A3, B2, C3 etc. The number of each type of scheme is then determined for later use in developing an operation cost estimate (see Fig. 4).

This tool lays the foundation for comparing a mix of project types in one area with another.

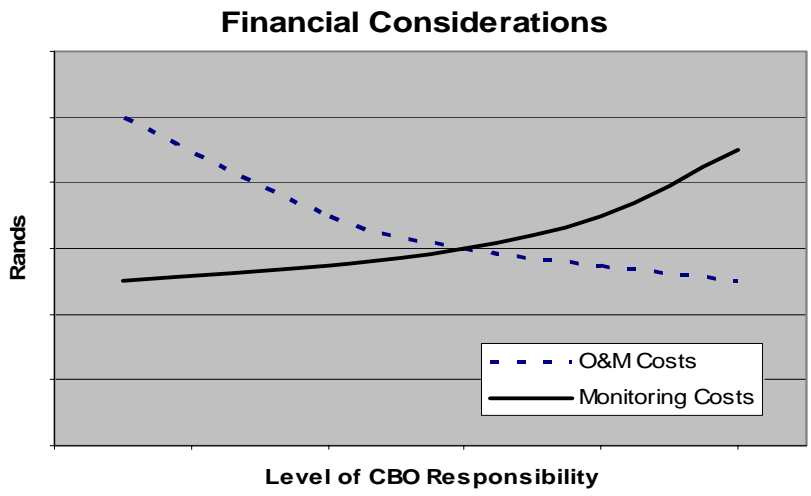

Figure 3

Indication of increasing monitoring costs as $\mathrm{CBO}$ responsibility increase

TABLE 2

Principles of ANDM scheme classification system

\begin{tabular}{|l|c|l|}
\hline Parameter & Class & Description \\
\hline & A & $10-17$ villages (15 000 - 25 000 people) \\
Scheme & B & $4-10$ villages (6 000 - 15 000 people) \\
Size & C & $2-4$ villages (1 500 - 6 000 people) \\
& D & 1 village (<1 500 people) \\
\hline & 1 & Treatment, power, reticulated \\
& 2 & Power, reticulated \\
Technology & 3 & Gravity, reticulated \\
& 4 & Gravity, no reticulation \\
& 5 & Pumped, no reticulation \\
& 6 & Handpump \\
\hline
\end{tabular}

Scheme Classification System

\begin{tabular}{|c|c|c|c|c|c|c|c|}
\hline \multicolumn{2}{|l|}{ Extent } & $\begin{array}{c}11-17 \text { villages } \\
10000<\text { pop }>25000\end{array}$ & & $\begin{array}{l}.0 \text { villages } \\
\text { <pop>10000 }\end{array}$ & $\begin{array}{c}2-4 \text { villages } \\
1500<\text { pop }>5000\end{array}$ & $\begin{array}{l}\text { 1 village } \\
\text { Pop }<1500\end{array}$ & \multirow{8}{*}{$\begin{array}{c}\text { Figure } 4 \\
\text { Scheme classification } \\
\text { system for portion of } \\
\text { ANDM }\end{array}$} \\
\hline \multicolumn{2}{|l|}{ Tech } & $A$ & & B & C & $\mathrm{D}$ & \\
\hline $\begin{array}{l}\text { Treat/ } \\
\text { Powerl } \\
\text { Retic }\end{array}$ & 1 & 1 & & & & & \\
\hline Power/ Retic & 2 & & 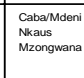 & 3 & 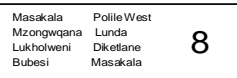 & 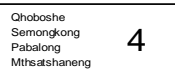 & \\
\hline $\begin{array}{l}\text { Gravityl } \\
\text { Retic }\end{array}$ & 3 & 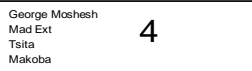 & \begin{tabular}{|l|l|} 
Tital \\
Thaba chingia
\end{tabular} & 2 & 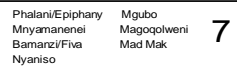 & 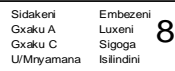 & \\
\hline $\begin{array}{c}\text { Gravity (no } \\
\text { Retic) }\end{array}$ & 4 & & & & & $\begin{array}{ll}\begin{array}{l}\text { Bethesesta } \\
\text { Marias }\end{array} & \\
& \end{array}$ & \\
\hline$\underset{\text { Pumped (no }}{\text { Retic) }}$ & 5 & & & & & & \\
\hline $\begin{array}{l}\text { Hand } \\
\text { Pump }\end{array}$ & 6 & & & & 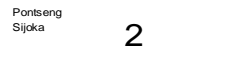 & $\begin{array}{l}\text { Good hope } \\
\end{array}$ & \\
\hline
\end{tabular}

\section{Resource identification}

The resource allocation is developed on the basis of a quantity of each resource required to complete the tasks as defined as necessary for each generic scheme type (i.e. A1 through D6).
Resource types are as follows:

- Board members

- Operators

- Administrators

- Managers 
Figure 5

Example output from ANDM cost model
- Technicians

- ISD f/workers

- Vehicles

- $\quad$ Spares and equipment

The allocation of time requirements is done in consultation with all stakeholders in a workshop environment. It is imperative that the WSA clearly defines the tasks required so that the correct resources are allocated for each type of scheme. For example, frequency of water quality testing on scheme supplying a population of 17000 must be compared with one that supplies a population of less than 1000 .

\section{Cost model}

Once schemes for an area have been classified and resources allocated, a cost estimate can be produced on the basis of rates that are allocated to the resources listed above. Then by entering the relevant number of schemes of each type (A1 - D6) it is possible to determine a cost estimate and compare different areas of operation with a dissimilar scope of work on a fair basis. It must be noted that the WSA needs to be realistic in that it may be more cost effective not to fulfil certain tasks at all or that it may be more cost effective for another organisation to fulfil a particular function. For example, it proved to be more expensive to collect tariffs on rural schemes than the value of the tariffs actually collected, and hence the implementation of FBW. This point requires careful consideration where the WSA may want to collect tariffs from higher levels of service connections consuming more water than the FBW allocation.

An example of the relative cost per capita for different scheme types is shown in Fig. 5. It should be noted that clustering of smaller projects into a "higher class", where practical, will have significant cost saving implications. CBO in their monthly report so the WSA can have confidence that information is flowing from project level and is not only the observation of outsiders. In cases such as water quality where it is

A series of parameters have been identified for constant monitoring and reporting (Still, 2002). The objective was to develop a tool that supplied the client with information that was sufficient in detail that a clear picture of operations could be determined from the reports. It was however recognised that the collection of data is a costly and difficult exercise in rural areas. The parameters identified were:

\begin{tabular}{|c|c|}
\hline \multicolumn{2}{|c|}{$\begin{array}{c}\text { TABLE } 3 \\
\text { O\&M monthly reporting system }\end{array}$} \\
\hline Management focus area & Parameter \\
\hline Quality of water supplied & e-coli count per $100 \mathrm{~m} \ell$ \\
\hline $\begin{array}{l}\text { Quantity of water } \\
\text { supplied/consumed }\end{array}$ & $\begin{array}{l}\% \text { of FBW: \% of sufficiency of } \\
\text { source }\end{array}$ \\
\hline Continuity of supply & \% tap-days operational \\
\hline Financial & Cost per cap: \% of budget \\
\hline Performance of CBOs & Meetings: Reports: Commitment \\
\hline $\begin{array}{l}\text { Reporting of serious } \\
\text { incidents }\end{array}$ & Incident reports and register \\
\hline $\begin{array}{l}\text { Servicing and repair } \\
\text { records }\end{array}$ & $\begin{array}{l}\text { Register of medium and major } \\
\text { maintenance }\end{array}$ \\
\hline $\begin{array}{l}\text { Sanitation status at each } \\
\text { project }\end{array}$ & $\begin{array}{l}\% \text { population with facilities: health } \\
\text { reports }\end{array}$ \\
\hline
\end{tabular}




\begin{tabular}{|c|c|}
\hline \multicolumn{2}{|c|}{$\begin{array}{l}\text { TABLE } 4 \\
\text { Rural water service provision: ANDM benchmarks }\end{array}$} \\
\hline Management focus area & Current benchmarks \\
\hline Quality of water supplied & $\begin{array}{l}\text { Sampled monthly on all projects } \\
0 \text { e-coli = good } \\
0 \text {-10 e-coli = acceptable } \\
\text { Greater than } 10 \text { e-coli = poor }\end{array}$ \\
\hline Quantity of water & $\begin{array}{l}10 \ell \text { per capita per day (RDP service) } \\
15 \mathrm{k} \ell / \text { month ( private connections) }\end{array}$ \\
\hline Continuity of supply & $\begin{array}{l}>98 \% \text { tap-days operational = good } \\
80 \% \text { - } 98 \% \text { tap-days operational } \\
=\text { poor } \\
<80 \% \text { tap-days operational } \\
=\text { unacceptable }\end{array}$ \\
\hline Financial & $\begin{array}{l}\text { Cost per capita ranges from R1.58 } \\
\text { to R3.16 for a population of } 390000 \\
\text { people }\end{array}$ \\
\hline Performance of CBOs & $\begin{array}{l}\text { Meetings held and minutes submitted } \\
\text { each month. } \\
\text { Reports submitted monthly. }\end{array}$ \\
\hline
\end{tabular}

not practical for CBOs to give lab test results qualitative responses are indicated in their reports.

\section{Benchmarks}

The two years of experience gained on this programme have enabled the ANDM to establish a series of benchmarks. These benchmarks may only be applicable in a specific environment and it is anticipated that in other circumstances better achievements will be possible and worse performance may be inevitable. However they are provided here as an indication of what can be achieved in the provision of water supply services in a "deep rural" area of South Africa.

\section{Conclusions}

- CBOs have a significant role to play in rural water service provision, especially in day-to-day operations, reporting and customer relations.

- The use of CBOs improves the level of service that could otherwise be offered in remote rural areas due to their ability to respond immediately to breakdowns.

- The use of CBOs is cost effective.

- Realistic and appropriate targets for CBOs must be set, clearly defined and monitored

- The use of a systematic approach to defining targets and developing systems will enable the implementation of appropriate quality management systems.

- Once finalised, KPIs and milestones can serve as a basis for contractual agreements between the WSA and WSPs.

- Critical to the success of any O\&M plan for rural schemes lies with the identification of the KPAs and the definition of the level of service.

- The continual development of organisational capacity within local government and CBOs must be considered as a critical component of the O\&M plan and the systems to be adopted.

\section{References}

ALFRED NZO DISTRICT MUNICIPALITY (2000) Village Level Action Plan.

STILL D (2002) Private communication. Partners in Development.

WATER RESEARCH COMMISSION (WRC) (2003) Making Water Work for Villages, WRC Report TT 216/03. 